American Journal of Applied Sciences 8 (7): 736-739, 2011

ISSN 1546-9239

(C) 2011 Science Publications

\title{
Inter-Area Power Systems Stability Improvement by Static Synchronous Series Compensator
}

\author{
Prechanon Kumkratug \\ Department of Electrical Engineering, Faculty of Engineering at Si Racha, \\ Kasetsart University, 199 M.6, Tungsukhla, Si Racha, Chonburi, 20230, Thailand
}

\begin{abstract}
Problem statement: The inter-area power systems have special characteristic of the stability behavior. The improvement of inter-area power system is one of the important aspects in power system. Approach: This study applies the Static Synchronous Series Compensator (SSSC) to improve stability of inter-area systems. The SSSC is modeled and then is applied to be incorporated into the power system model for investigating stability improvement. The SSSC is modeled as the variable susceptance and is controlled during dynamic state. This presented SSSC model can be incorporated into susceptance matrix of power system model. The presented method is tested on sample inter-area power system with 3 phase fault distubrances. Results: The swing curve of inter-area power system without a SSSC gets increases monotonically and thus the system can be considered as unstable whereas the swing curves of system with a SSSC can be considered as stable. Conclusion: From the simulation results, the SSSC can enhance stability of inter-area power systems.
\end{abstract}

Key words: Power system, Static Synchronous Series Compensator (SSSC), Flexible AC Transmission System (FACTS), injected current, synchronous, thyristor controlled phase shifter, series transformer, voltage source, leakage reactance, inter-area power system

\section{INTRODUCTION}

Because of growing demand in electrical energy, Modern power system network is getting much more complicated than ever before. Some power systems are linked between two area "inter-area power systems". The inter-area power systems have special characteristic of stability behavior. The improvement of inter-area power system is one of the important aspects in power system. There are many advanced devices have been proposed during the last three decades to improve stability of power system such as High Voltage Direct Current (HVDC) system and Flexible AC Transmission System (FACTS) devices (Al-Husban, 2009; Mota and Mota, 2011; Bana Sharifian et al., 2009; Chen, 2011; Jia-Liang et al., 2010; Magaji and Mustafa, 2009a; Nisar et al., 2009).

A Static Synchronous Series Compensator (SSSC) is a member of the FACTS family that is connected in series with power system. The SSSC consists of a solid state voltage source converter with GTO thyristor switches or other high performance of semi-conductor and transformer. The SSSC can electrically mimic reactor and capacitor by injecting a shunt current in quadrature with the line voltage. The reactive power (or current) of the SSSC can be adjusted by controlling the magnitude and phase angle of the output voltage of the shunt converter (Magaji and Mustafa, 2009b; Kumkratug, 2011a; 2011b; El-Shennawy et al. 2010). This study applies the Static Synchronous Series Compensator (SSSC) to improve stability of interarea systems. This study presents the method to incorporate SSSC model into the inter-area power system for investigating stability improvement. The simulation results are tested on a sample inter-area power system.

\section{MATERIALS AND METHODS}

Mathematical model: Consider power system consisting $\mathrm{n}_{\mathrm{g}}$ generators and equipped a SSSC between bus $m$ and bus $n$ as shown in Fig. 1. Figure 2 shows the equivalent circuit diagram of Fig. 1. The $E^{\prime}$ is the transient voltage of generator and the $\mathrm{Y}^{\mathrm{int}}$ is the reduced admittance matrix of power system. The SSSC can be represented by the series voltage injection $\mathbf{V}_{\mathrm{s}}$ and $\mathrm{X}_{2}$ is the reactance equivalent of a series transformer and line between bus $m$ and $n$.

The voltage source and the reactance can be transformed into the current source as shown in Fig. 3 and given by:

$I_{s s}=\frac{V_{s}}{j X_{2}}=-j a b e^{j \alpha} V_{m}$ 


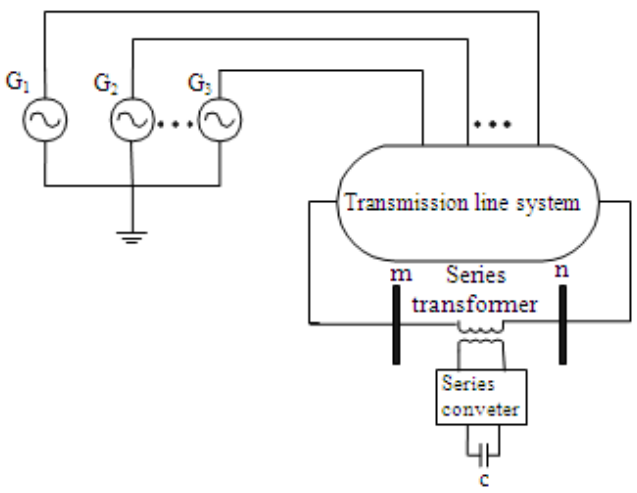

Fig. 1: Power system with a SSSC

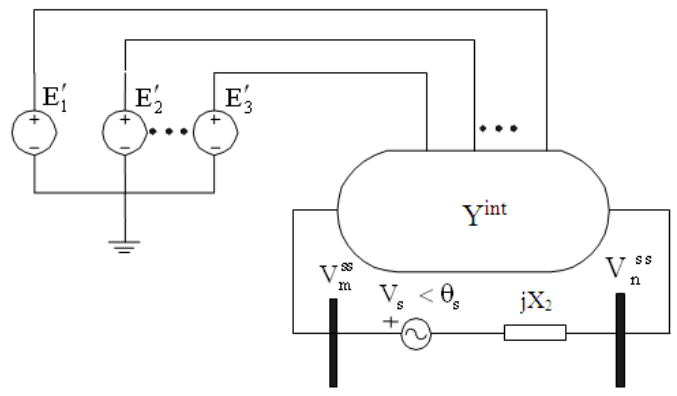

Fig. 2: The equivalent circuit of the power system with a SSSC represented by a series voltage source and leakage reactance

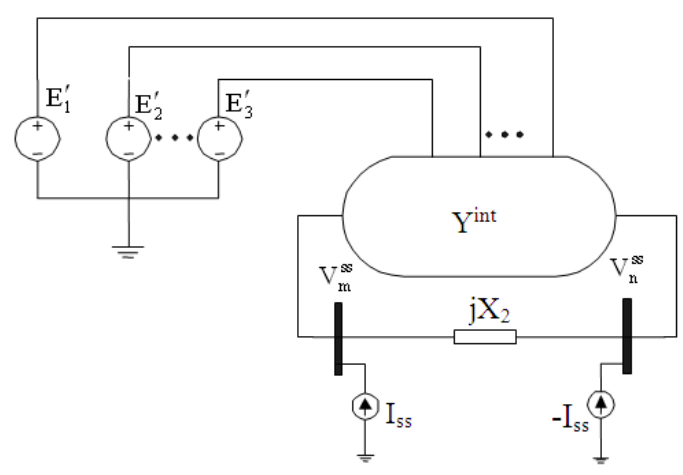

Fig. 3: The equivalent circuit of the power system with a SSSC represented by a series current source

Here:

$\mathrm{a} \angle \alpha=\frac{\mathrm{V}_{\mathrm{s}} \angle \theta_{\mathrm{s}}}{\mathrm{V}_{\mathrm{m}}^{\mathrm{ss}} \angle \theta_{\mathrm{m}}^{\mathrm{ss}}}$

The complex power injection at bus $\mathrm{m}$ as shown Fig. 4 is given by:
$\mathrm{S}_{\mathrm{mi}}^{\mathrm{ss}}=\mathrm{P}_{\mathrm{mi}}^{\mathrm{ss}}+\mathrm{jQ} \mathrm{Q}_{\mathrm{mi}}^{\mathrm{ss}}=\mathrm{V}_{\mathrm{m}}^{\mathrm{ss}}\left(-\mathrm{I}_{\mathrm{ss}}\right)^{*}$

$=\mathrm{V}_{\mathrm{m}}^{\mathrm{ss}} \angle \theta_{\mathrm{m}}^{\mathrm{ss}}\left(-\mathrm{ab} \mathrm{V}_{\mathrm{m}}^{\mathrm{ss}} \angle\left(\alpha-90+\theta_{\mathrm{m}}^{\mathrm{ss}}\right)\right)^{*}$

$=-\mathrm{ab}\left(\mathrm{V}_{\mathrm{m}}^{\mathrm{ss}}\right)^{2} \angle(90-\alpha)$

$=-\mathrm{ab}\left(\mathrm{V}_{\mathrm{m}}^{\mathrm{ss}}\right)^{2} \sin \alpha-\mathrm{jab}\left(\mathrm{V}_{\mathrm{m}}^{\mathrm{ss}}\right)^{2} \cos (\alpha)$

The real power injection at bus $m$ is given by:

$\mathrm{P}_{\mathrm{mi}}^{\mathrm{ss}}=-\mathrm{ab}\left(\mathrm{V}_{\mathrm{m}}^{\mathrm{ss}}\right)^{2} \sin \alpha$ by:

And the reactive power injection at bus $\mathrm{m}$ is given

$\mathrm{Q}_{\mathrm{mi}}^{\mathrm{ss}}=-\mathrm{ab}\left(\mathrm{V}_{\mathrm{m}}^{\mathrm{ss}}\right)^{2} \cos (\alpha)$

Similarly, the complex power injection at bus $\mathrm{n}$ as shown Fig. 5 is given by:

$\mathrm{S}_{\mathrm{ni}}^{\mathrm{ss}}=\mathrm{P}_{\mathrm{ni}}^{\mathrm{ss}}+\mathrm{j} \mathrm{Q}_{\mathrm{ni}}^{\mathrm{ss}}=\mathrm{V}_{\mathrm{n}}^{\mathrm{ss}}\left(\mathrm{I}_{\mathrm{ss}}\right)^{*}$

$=\mathrm{V}_{\mathrm{n}}^{\mathrm{ss}} \angle \theta_{\mathrm{n}}^{\mathrm{ss}}\left(a b \mathrm{~V}_{\mathrm{m}}^{\mathrm{ss}} \angle\left(\alpha-90+\theta_{\mathrm{m}}^{\mathrm{ss}}\right)\right)^{*}$

$=\mathrm{abV}_{\mathrm{m}}^{\mathrm{ss}} \mathrm{V}_{\mathrm{n}}^{\mathrm{ss}} \angle\left(90-\left(\theta_{\mathrm{m}}^{\mathrm{ss}}-\theta_{\mathrm{n}}^{\mathrm{ss}}+\alpha\right)\right)$

$=a b V_{m}^{s s} V_{n}^{s s} \sin \left(\theta_{m n}^{s s}\right)+j a b V_{n}^{s s} \bigvee_{m}^{s s} \cos \left(\theta_{m n}^{s s}+\alpha\right)$

The real power injection at bus $\mathrm{n}$ is given by:

$\mathrm{P}_{\mathrm{ni}}^{\mathrm{ss}}=\mathrm{ab} \mathrm{V}_{\mathrm{m}}^{\mathrm{ss}} \mathrm{V}_{\mathrm{n}}^{\mathrm{ss}} \sin \left(\theta_{\mathrm{mn}}^{\mathrm{ss}}\right)$

and the reactive power injection at bus $\mathrm{n}$ is given by:

$\mathrm{Q}_{\mathrm{ni}}^{\mathrm{ss}}=\mathrm{abV}_{\mathrm{n}}^{\mathrm{ss}} \mathrm{V}_{\mathrm{m}}^{\mathrm{ss}} \cos \left(\theta_{\mathrm{mn}}^{\mathrm{ss}}+\alpha\right)$

From the complex power injections as given in (4), (5), (7) and (8) associated with line voltages, they can be represented by the admittance at bus $\mathrm{m}$ as bus $\mathrm{n}$ as shown in Fig. 6 and given by:

$Y_{\mathrm{mi}}^{\mathrm{ss}}=\frac{P_{\mathrm{mi}}^{\mathrm{ss}}-j Q_{\mathrm{mi}}^{\mathrm{ss}}}{\left(\mathrm{V}_{\mathrm{m}}^{\mathrm{ss}}\right)^{2}}$

$\mathrm{Y}_{\mathrm{ni}}^{\mathrm{ss}}=\frac{\mathrm{P}_{\mathrm{ni}}^{\mathrm{ss}}-\mathrm{j} \mathrm{Q}_{\mathrm{ni}}^{\mathrm{ss}}}{\left(\mathrm{V}_{\mathrm{n}}^{\mathrm{ss}}\right)^{2}}$

Dynamic equation: The dynamic equations of power system are written by:

$\dot{\delta}_{\mathrm{i}}=\omega_{\mathrm{i}}$

$\dot{\omega}_{\mathrm{i}}=\frac{1}{\mathrm{M}_{\mathrm{i}}}\left[\mathrm{P}_{\mathrm{mi}}-\mathrm{P}_{\mathrm{ei}}^{\mathrm{ss}}\right] \mathrm{i}=1,2 \ldots . \mathrm{n}_{\mathrm{g}}$ 
Here:

$\delta_{\mathrm{i}}=$ Generator rotor angle of the $\mathrm{i}$-th generator

$\omega_{\mathrm{i}}=$ Generator speed of the $\mathrm{i}$-th generator

$\mathrm{P}_{\mathrm{mi}}=$ Input mechanical power of the $\mathrm{i}$-th generator

$\mathrm{P}_{\mathrm{ei}}=$ Output electrical power of the $\mathrm{i}$-th generator

The output electrical power of i-th generator with can be written by:

$\mathrm{P}_{\mathrm{ei}}=\operatorname{Re}\left[\mathrm{E}_{\mathrm{i}}^{\prime} \mathrm{I}_{\mathrm{Gi}}\right]$

Here the generator current injection $\left(\mathrm{I}_{\mathrm{G}}\right)$ as given in (13) can be obtained by multiplying the $\mathrm{E}_{\mathrm{G}}$ with the $\mathrm{Y}_{\mathrm{ss}}^{\mathrm{int}}$.

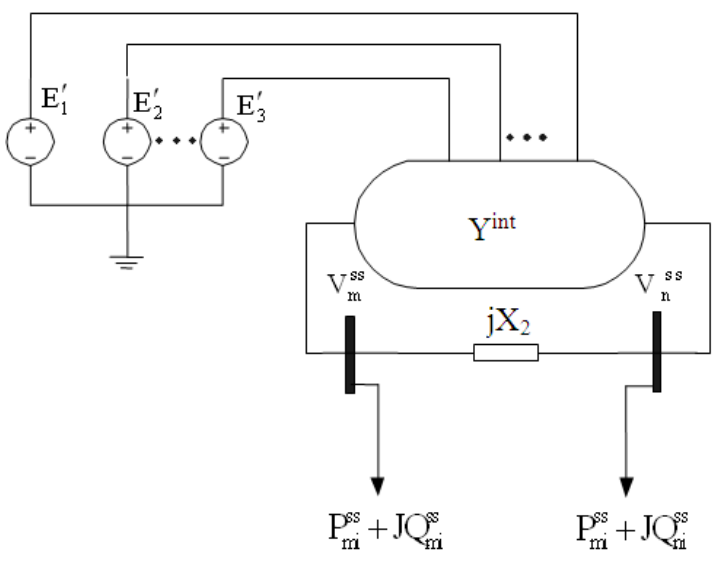

Fig. 4: The equivalent circuit of the power system with a SSSC represented by complex power injections

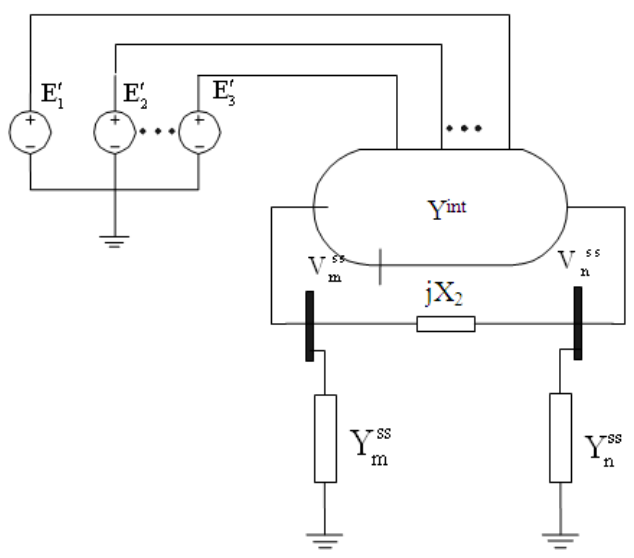

Fig. 5: The equivalent circuit of the power system with a SSSC represented by the reactances
RESULTS

The presented method of improving stability of inter-area power system by a SSSC is tested on a sample system as shown in Fig. 7. The system consists of 4 generators, 4 transformers and 11 buses. A SSSC is equipped between area 1 (generator 1 and generator 2) and area 2 (generator 3 and generator 4). It is considered that a three phase fault appears at bus 8 at $100 \mathrm{msec}$ and it is cleared at $180 \mathrm{msec}$. Figure 8 shows the swing curve of the system without a SSSC and Fig. 9 shows the swing curve of the system with a SSSC.

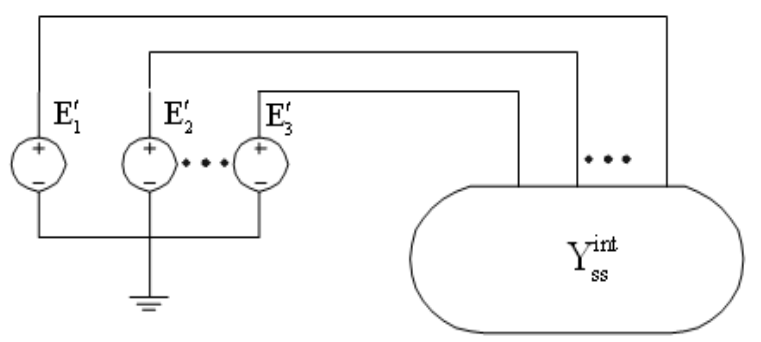

Fig. 6: The successive equivalent circuit of the power system with a SSSC represented by reduced admittance

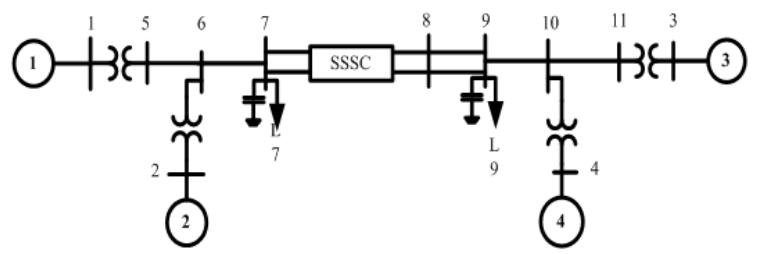

Fig. 7: Inter-area power system with a SSSC

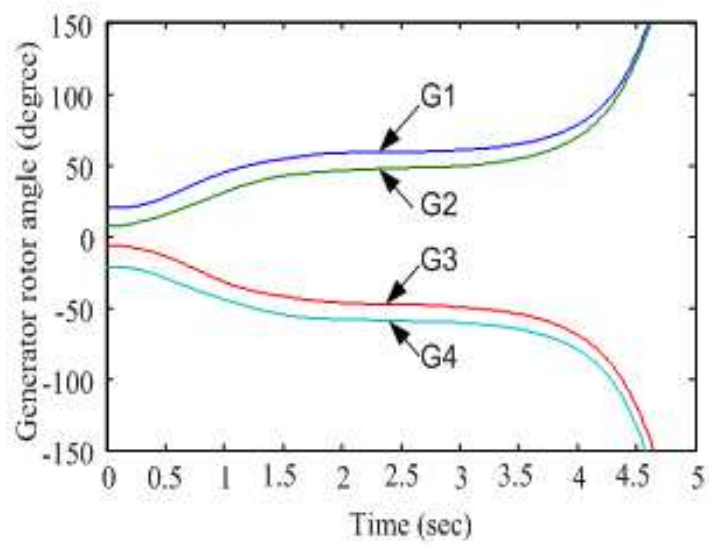

Fig. 8: Swing curve of Inter-area power system without a SSSC 


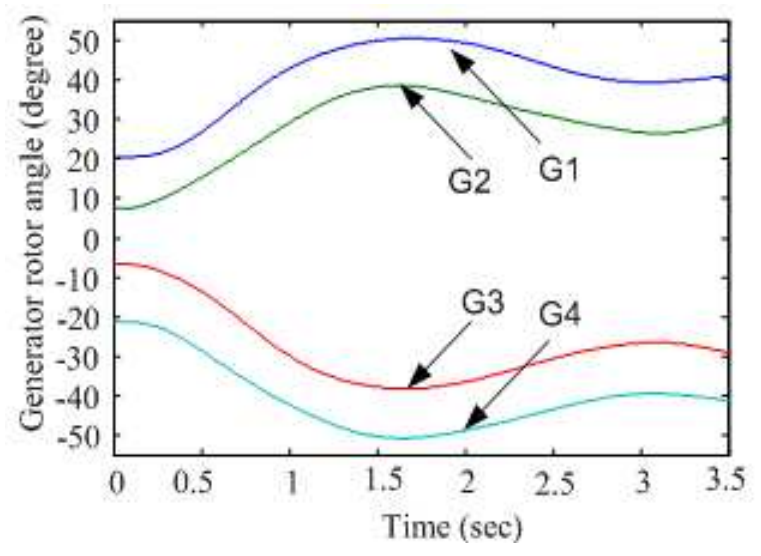

Fig. 9: Swing curve of Inter-area power system with a SSSC

\section{DISCUSSION}

It can be observed from the simulation results as shown in Fig. 8-9 that without a SSSSC the different angles of generator in area 1 and area 2 increases significantly and thus the system is considered as unstable. However, with a SSSC, the system is considered as stable. It indicates that a SSSC can enhance stability of the inter-area power system.

\section{CONCLUSION}

This study investigates the capability of the Static Synchronous Series Compensator (SSSC) on stability enhancement of the inter-area power system. The mathematical model is systematically derived. The SSSC is modeled and then is applied to be incorporated into the power system model for investigating stability improvement. The SSSC is modeled as the variable susceptance and is controlled during dynamic state. This presented SSSC model can be incorporated into susceptance matrix of power system model.

The presented method is tested on sample interarea power system with 3 phase fault disturbances. The swing curve of inter-area power system without a SSSC gets increases monotonically and thus the system can be considered as unstable whereas the swing curves of system with a SSSC can be considered as stable. It indicates that a SSSC can enhance stability of the interarea power system.

\section{REFERENCES}

Al-Husban, A.N., 2009. An eigenstructure assignment for a static synchronous compensator. Am. J. Eng. Applied Sci., 2: $\quad 812-816 . \quad$ DOI: 10.3844/ajeassp.2009.812.816

Bana Sharifian, M.B., Y. Mohamadrezapour, M. Hosseinpour and S. Torabzade, 2009. Maximum power control of variable speed wind turbine connected to permanent magnet synchronous generator using chopper equipped with superconductive inductor. J. Applied Sci., 9: 777782. DOI: $10.3923 /$ jas.2009.777.782

Chen, G., 2011. Dynamic optimal power flow in FSWGs integrated power system. Inform. Technol. J., 10: 385-393. DOI: 10.3923/itj.2011.385.393

El-Shennawy, T.I., A.-M. Moussa, M.A. El-Gammal and A.Y. Abou-Ghazala, 2010. A dynamic voltage restorer for voltage sag mitigation in a refinery with induction motors loads. Am. J. Eng. Applied Sci., 3 : 144-151. 10.3844/ajeassp.2010.144.151

Jia-Liang, G., Z. Hong-Xia and Z. Jin, 2010. Fuzzy logic based current control schemes for vectorcontrolled asynchronous motor drives. Inform. Technol. J., 9: 1495-1499. DOI: 10.3923/itj.2010.1495.1499

Kumkratug, P., 2011a. Nonlinear control design of series FACTS Devices for damping power system oscillation. Am. J. Applied Sci., 8: 124-128. DOI: 10.3844/ajassp.2011.124.128

Kumkratug, P., 2011b. Improving power system transient stability with static synchronous series compensator. Am. J. Applied Sci., 8: 77-81. DOI: 10.3844/ajassp.2011.77.81

Magaji, M. and M. W. Mustafa, 2009a. Optimal thyristor control series capacitor neuro-controller for damping oscillations. J. Comput. Sci., 5: 980987. DOI: $10.3844 /$ jcssp.2009.980.987

Magaji, M. and M.W. Mustafa, 2009b. Optimal location of static var compensator device for damping oscillations. Am. J. Eng. Applied Sci., 2: 353-359. DOI: 10.3844/ajeassp.2009.353.359

Mota, A.A. and L.T.M. Mota, 2011. Drawing meshed one-line diagrams of electric power systems using a modified controlled spring embedder algorithm enhanced with geospatial data. J. Comput. Sci., 7: 234-241. DOI: 10.3844/jcssp.2011.234.241

Nisar, M.W., W. Yong-Ji, M. Elahi and I.A. Khan, 2009. Software development effort estimation using fuzzy logic. Inform. Technol. J., 8: 347-353. DOI: $10.3923 /$ itj.2009.347.353 